\title{
A Special Issue of the Canadian Journal of Learning and Technology on Knowledge Building
}

\section{Michele Jacobsen}

In contrast to an open issue of CJLT, in which a variety of research and scholarship from across the educational technology spectrum is presented, a special issue is typically devoted to a particular domain or specific topic of research interest in the field of educational technology.

In a pervasive media and technology landscape that is increasingly global, participatory and connected, one in which learners and teachers can increasingly become creators of knowledge rather than mere consumers of prepared messages and ideas, it is vital for the field of educational technology to take stock of the latest research on knowledge building. Marlene Scardamalia and Carl Bereiter, innovative pioneers in the area of Knowledge Building in education, define the construct of Knowledge Building as having several characteristics that distinguish it from constructivist learning in general. Two key characteristics of Knowledge Building are intentionality and community knowledge. Intentionality captures that people engaged in knowledge building know they are doing it and that advances in knowledge are purposeful. Community knowledge captures that while learning is a personal matter, knowledge building is done for the benefit of the community. Scardamalia and Bereiter emphasize that in contrast to being spontaneous, a knowledge building culture requires a supportive learning environment and teacher effort and artistry to create and maintain a community devoted to ideas and to idea improvement. Distinct from improving individual students' ideas and understanding, the collective work of Knowledge Building is explicitly focused on the creation and improvement of knowledge of value to one's community - advancement of the knowledge itself.

Educators and the education system need to be responsive to both the opportunities and challenges that participatory social networks and pervasive technologies present it is clear that major changes to our familiar notions of learning as an individual endeavour and technology as mere tool are needed. Scardamalia and Bereiter's own research on Knowledge Building, and the extended community of researchers that they have cultivated and inspired, offer sound principles and theory to guide pedagogical practices and disciplined research on technology-enabled learning and teaching that matters in the twenty-first century.

This special issue on Knowledge Building is unique in that it consists of 16 articles that span two volumes of CJLT. In Winter 2009, CJLT published five research papers on Knowledge Building that were shepherded through the peer review and editing process by Marlene Scardamalia, OISE / Univeristy of Toronto, and Bill Egnatoff, Queens University. To accompany the present Winter 2010 issue, the editorial team presents again the five articles that reflect diverse research on Knowledge Building. The nine authors who contributed their research and critical perspectives on Knowledge Building 
to the Winter 2009 issue hail from post-secondary institutions in Canada, Australia and China.

This Winter 2010 special issue of CJLT contains eleven articles that capture state of the art research and theory on Knowledge Building by thirty authors from across Canada, the United States, Finland, Italy, the Netherlands, Spain and Taiwan. The research on Knowledge Building in this issue spans elementary school classroom settings to campus classrooms in education, science, medicine and health science contexts. Articles in this special issue provide convincing examples of what young and mature students can do in knowledge building classrooms - academically rigorous and authentic work that compares favorably with what professionals do that gets credited as knowledge creation.

In the introductory paper to this issue, entitled, "A Brief History of Knowledge Building", Scardamalia and Bereiter provide an overview of their work in Knowledge Building research and practices in education over the past few decades. From their seminal work on experts and expertise in the early 1990s, in which they distinguished between progressive problem solving and cognitive reinvestment, and competent performance focused on problem reduction (Bereiter \& Scardamalia, 1993), they trace a trajectory to the design and development of computer supported learning environments and multimedia databases in the evolution of knowledge building.

A major development in the evolution of knowledge building was the use of networked technology in the context of disciplined inquiry to support student-to-student information sharing and feedback for idea improvement. In the early 1980s, Scardamalia and Bereiter designed CSILE (Computer Supported Intentional Learning Environment) to support the collaborative construction of community knowledge. CSILE was built upon the belief that students themselves represented an important knowledge resource in the classroom that could be brought into play via networked technology (Scardamalia \& Bereiter, 2006). As a game changer, CSILE disrupted the flow of information in the classroom - students' ideas, questions, criticisms and suggestions were contributed to a public space that was equally accessible to all, rather than information flowing from and through the teacher. By linking contributions, students created an emergent hypertext that represented collective, community knowledge rather than just the individual knowledge of participants (Scardamalia \& Bereiter, 2006).

A major redesign of CSILE in the 1990s focused on developing the next generation of this knowledge building environment to support collaborative work aimed at idea improvement and community knowledge. Knowledge Forum ${ }^{\circledR}$ provides an environment for communities to carry on the sociocognitive practices that are constitutive of knowledge and innovation-creating organizations (Scardamalia \& Bereiter, 2006). Knowledge Forum ${ }^{\circledR}$ is a multimedia database that has been designed, and undergoes continual revision as theory advances and experience uncovers new problems and opportunities, to maximize the ability of a community to create and improve both its 
content and organization. Distinct from threaded discussions, users have control over notes and views and the organization and creation of ideas in the database. Knowledge Forum ${ }^{\circledR}$ also provides scaffolds to help shape discourse for knowledge building purposes - the use of scaffolds is optional and can be modified as knowledge building progresses.

In their brief history of knowledge building, Scardamalia and Bereiter present twelve "Knowledge Building principles" which have been developed and can serve multiple purposes, from pedagogical guides to evaluating existing practices, to informing and guiding scholarship in the discipline, as evidenced by the fourteen research studies in the Winter 2010 and 2009 issues of CJLT that amplify and investigate these principles in practice. Building and extending upon the solid foundation built by these knowledge building pioneers, the authors in this issue contribute new understanding and evidence based recommendations for this growing area of scholarship in the field of educational technology.

For those who want to explore a more complete published account of Knowledge Building pedagogy and technology, there is a chapter in the Cambridge Handbook of the Learning Sciences (Scardamalia \& Bereiter, 2006) that is well worth a read. In that chapter, Scardamalia and Bereiter (2006) articulate six themes that illustrate the shift from treating students as individual learners and inquirers to treating them as members of a knowledge building community:

- Knowledge building as a community rather than individual achievement

- Knowledge building as idea improvement rather than as progress toward true or warranted belief

- Knowledge of in contrast to knowledge about

- Discourse as collaborative problem solving rather than as argumentation

- Constructive use of authoritative information

- Understanding as an emergent

In the concluding paper for this special issue, Bereiter and Scardamalia invite us to consider the possibilities and innovations in thinking about children's knowledge building and thinking, and to imagine what lies ahead. Two questions orient the discussion: 1) Does genuine knowledge creation have to wait until graduate school? 2) Does existing knowledge have to be mastered before students can venture into knowledge innovations themselves? In a thought provoking conclusion to this two part special issue of CJLT on Knowledge Building, Bereiter and Scardamalia challenge us to move beyond information sharing and surface uses of technology to embrace the intentional knowledge building practices, technology enabled environments and knowledge creating cultures that our communities need for social progress of all kinds and to address the problems and situations that we encounter as a society. 
It has been a privilege to work closely with Marlene Scardamalia, Susana Rosa and Maureen Washington on the manuscripts that authors entrusted to the journal and to prepare this special issue of CJLT. From the student who fell in love with your book Surpassing Ourselves so many years ago, thank you Carl and Marlene for advancing the state of knowledge of Knowledge Building in the learning sciences and in the field of educational technology.

\section{References}

Bereiter, C., \& Scardamalia, M. (1993). Surpassing ourselves: An inquiry into the nature and implications of expertise. La Salle, IL: Open Court.

Scardamalia, M., \& Bereiter, C. (2006). Knowledge Building: Theory, pedagogy, and technology. In K. Sawyer (Ed.), Cambridge Handbook of the Learning Sciences (pp. 97-118). New York: Cambridge University Press. 